\title{
Preparation for Adulthood: \\ A Teacher Inquiry Study for Facilitating Life Skills in Secondary Education in the United States
}

\author{
Kelly Cassidy (Corresponding author) \\ Graduate Student, University of Tampa \\ 401 W. Kennedy Blvd. Tampa, Florida 33606, United States \\ E-mail: kelly.cassidy@spartans.ut.edu \\ Yvonne Franco, Ph.D. \\ Professor of Education, University of Tampa \\ 401 W. Kennedy Blvd. Tampa, Florida 33606, United States \\ E-mail: yfranco@ut.edu
}

\section{Emilia Meo}

Graduate Student, University of Tampa

401 W. Kennedy Blvd. Tampa, Florida 33606, United States

E-mail: emilia.meo@spartans.ut.edu

Received: January 12, 2018 Accepted: March 1, 2018 Published: March 3, 2018

doi:10.5296/jei.v4i1.12471 URL: https://doi.org/10.5296/jei.v4i1.12471

\begin{abstract}
Life skills preparation for adulthood is a crucial, yet often overlooked concept in education. In schools across the United States, young adults graduate from high school with limited knowledge regarding how to navigate through the expectations of the real world. Although many educators feel teaching life skills in the classroom is necessary, the frustration of needing to adhere to state standards and lack of time often interferes with their implementation. This is unfortunate, as research indicates, "life skills education bridges the gap between basic functioning and capabilities. It strengthens the ability of an individual to meet the needs and
\end{abstract}


demands of the present society, and helps in dealing with issues in a practical manner" (Prajapati, B. Sharma, \& D. Sharma, 2017, p. 1). This action research study investigates ways two teachers implemented realistic life skill lessons, while adhering to district standards. Strategies investigated include: interest surveys, goal setting and social skills instruction.

Keywords: Life skills, Adulthood, Standards

\section{Introduction}

Education, though constantly evolving, has one primary goal: to prepare students to be independent, responsible members of society. Though standards and curriculum change over time, one thing that remains constant is the necessity for life skills to aid students in their navigation through adulthood. Schools today are obsessively focused on meetings standards, teaching from scripted curriculum, and meeting test benchmarks. In the process of it all, it is easy for educators to lose track of teaching the whole child. As high school educators with varied levels of experience in the field, we recognized our students were being taught to regurgitate information upon request, rather than to think, plan, and act independently. We found ourselves forgetting to teach the whole child, with the understanding that life skills played a significant part in their future success.

Whilst many believe education is meant solely for academics, we questioned the notion. Concepts like communication skills, goal setting, how to prepare a meal, budgeting, and time management are often expected to be 'picked up along the way' as students grow up. However, today's constantly evolving 'home life' structure, means many of our students lack a support system at home to teach the life skills necessary to thrive after graduation. According to UNICEF life skills are defined as psychosocial abilities for adaptive and positive behavior that enable individuals to deal effectively with the demands and challenges of everyday life. If students are never taught to specifically use and nurture these skills, society cannot expect them to be prepared for college, career, and most importantly, life. The concern is one shared by Rateau, Kaufman, and Cletzer, (2015), who state:

In our highly competitive and rapidly changing world, it is increasingly critical that college graduates enter the workforce with skills for lasting success. Yet, according to numerous studies, today's college graduates often venture into the workplace unprepared to meet the demands of today's employers (p. 60).

As our school year began, we noticed our high school students were blindly unaware of concepts they needed to understand and utilize as adults. Conversations with our students led us to sense a growing frustration over their lack of understanding related to life skills. They expressed a need for them, however did not have an understanding of what they were or how they need to be practiced and developed. Students began to question why life skills were not taught in their high school classes.

Strategic planning led us to consider implementing life skills into everyday lessons in order to respond to students' interests, desires, and needs. Moreover, an analysis of English standards indicated life skills were mildly embedded within them. For instance, students must initiate and participate effectively in a range of collaborative discussions (one-on-one, in groups, and 
teacher-led) with diverse partners on grades 9-10 topics, texts, and issues, building on others' ideas and expressing their own clearly and persuasively.

The standard highlights the expectation that high school students must master skills such as prioritizing, proper social skills, and collaboration. However, we could not assume our students would know ways to apply these skills beyond literary discussions, unless intentional instruction was designed. This led us to wonder, in what ways could we implement realistic life skill lessons, while adhering to district standards? We hoped the research question would teach us to use the required standards to prepare our students with basic life skills they could take with them upon graduation.

\subsection{Context and Cases}

Our research was conducted in two large charter schools, One Tree High (OTH) and Two Tree High (TTH). One Tree High serves students with a variety of special needs; all students who attend OTH have an Individual Education Plan. Due to the large number of free and reduced lunch population, this school is considered a Title I school. OTH is predominantly comprised of a Caucasian and African American population. Two Tree High is a collegiate charter high school that provides students with rigorous technology-enhanced education programs, in preparation for college and career tracks. TTH has a large African American and Hispanic population, and is not considered a Title I school.

David and Jerry are sophomores at OTH and are on the Autism Spectrum scale; both come from single parent homes. David lives with his mother and older brother, who are also on the Autism Spectrum. David is capable of social interactions and conversations, but often needs clarification and vivid explanations of the meaning behind a conversation. David has a 2.0 GPA, on access points. Access points serve students who are on an alternative diploma track. Jerry lives with his father and occasionally his older sister when she is in town. Jerry is much lower socially than David, and struggles to express himself appropriately. He has a 1.9 GPA, on access points. Both Jerry and David struggle to communicate with each other. David often becomes frustrated at Jerry's inability to express himself fully, which results in an outburst from David.

The students observed at TTH are also sophomores. They vary greatly in their academic levels, as well as their personalities and interests. Sylvie is a hard-working and motivated student. She has a 3.7 GPA, and plans to enroll part-time at the local Community College to earn an Associate's Degree before her High School graduation. Her hobbies include swimming and running. Sylvie's parents are very involved in her and her siblings' lives, and take their Catholic faith very seriously. Jeff shows a lot less academic enthusiasm than Sylvie. He is known as the "class clown," and focuses most of his energy on socializing with peers. Jeff is very interested in sports. His parents push him academically and enforce strict rules behaviorally. Despite this, his GPA is a 2.7 .

Like Sylvie, Grace is an enthusiastic student who works very hard in all aspects of school. She is on the volleyball team and hopes to continue playing during college. She also plans to enroll at the local community college, and works to maintain her current 3.2 GPA. Grace tries to avoid 
social issues at school, as she is very sensitive to others' opinions of her. Unlike Grace, Frank focuses a lot of time on his social life. He is academically motivated by his mother, whom also plays a large role in making sure Frank is respectful to the adults he encounters, as well as his peers. He plays baseball at the school and has a 3.7 GPA.

In this study, we also reached out to two recent graduates, Brooke and Nathan. Both students graduated from OTH on a standard diploma track, despite their disabilities, and are completing their first year at a community college. The students graduated OTH with a 3.6 GPA.

In addition to students, we required the insight and perspectives of fellow educators. We asked ten educators from varied positions at both charter schools, to provide us with the life skills they deemed most important for students to learn prior to graduation. The educators' teaching experience ranged from one year to twenty years.

\subsection{Literature Review}

The United Nations Children's Fund (2003) defines life skills as "psychosocial abilities for adaptive and positive behavior that enable individuals to deal effectively with the demands and challenges of everyday life. They are loosely grouped into three broad categories of skills, including, cognitive skills for analyzing and using information, personal skills for developing personal agency and managing oneself, and inter-personal skills for communicating and interacting effectively with others" (p. 1).

While education is important, learning to live life effectively is equally important. "Integrating life skill training through education will help youth to overcome such difficulties in life" (Prajapati, B. Sharma, \& D. Sharma, 2017, p. 1). Furthermore, life skill education aides in motivation, and provides social and self-management skills for various life experiences, as it addresses and incorporates the needs and interests of students. Research indicates the positive results of integrating life skills to bringing change to students' attitude, thoughts, and behaviors (Yadav \& Iqbal, 2009).

Sobel (2012), among researchers, advocates for life skill instruction, advocating "hands-on, real-world learning experiences, increase academic achievement, help students develop stronger ties to their community, enhance students' appreciation for the natural world, and create a heightened commitment to serving as active, contributing citizens" (p. 12). Addressing these global objectives, researchers offer varied perspectives regarding methods to arrive at them. Swank and Huber (2013) argue that "active engagement with community resources promotes opportunities to continue to learn pro-social behaviors and work skills, vocational education and aptitude beyond the school" (p. 78). Ramey (1984), however, believes the focus should be on the development of communication, and commitment to pursue personal goals. Researchers concur with attention to communication and goal setting, as socially competent people are able to use social experiences to meet their goals and needs, while understanding the needs and goals of others (Groeben, Perren, Stadelmann, \& Klitzing, 2011, as cited by Garrote, 2017).

The role of teachers is critical to promoting life skills that prepare students for adulthood. "The instruction will need to be supplemented by, or integrated with, the kinds of supports and other 
interventions currently offered by strong precollege outreach programs and school reform models" (Venezia \& Jaeger, 2013, p. 125). Pesce et al. (2016) evaluated the incorporation of movement into life skills' implementation and discovered the inclusion of movement while developing life skills not only assisted in physical gains, but also mental health gains. The researcher recommended students be provided freedom to move around the room, or the opportunity to work with a fidget device, as kinesthetic activities stimulate creativity and work production. Likewise, Meyer and Wurdinger (2016) assert kinesthetic activities are crucial, alongside recognizing student interests in the acquisition of life skills. Meyer expresses the importance of putting student interests at the center of life skills lessons and goal setting. In doing so, students are "developing ownership because they choose personally relevant projects and learn to self-monitor as they identify goals, resources, and timelines that enable them to accomplish tasks" (Meyer \& Wurdinger, 2016, p. 16).

\subsection{Purpose}

As younger educators only in our first and seventh year in the classroom, we understand the significance of acquiring life skills prior to attending college. Graduating high school with limited knowledge of concepts including goal setting, budgeting, time management, proper communication, ways to apply for a job, finance tactics, and more, is a detriment to success. This detriment was evident to us among our students as they prepared for basic classroom tests, and were unable to execute time management and goal setting skills. Despite the awareness of needed preparation, many were unable to adequately plan and prepare to ensure success on the exams.

Working at charter schools, we are empowered to plan the curriculum to include selected activities, objectives, and assessments, however, this too presents its limitations. Few state standards allow for content to be aligned with life skills. Thus, we would have to be innovative and creative in pursuing this endeavor.

Our challenge led us to wonder, in what ways can we implement realistic life skills while still adhering to district standards? In exploring this wondering, we hope to ignite discussion regarding ways to support the implementation of life skills in secondary classrooms.

This action research study may be of interest to students and educators alike. By incorporating student interests and potential future needs, lessons may become more engaging and meaningful to learners. In addition fellow educators may be interested in learning ways to prepare students for life after high school, through life skills implementation.

\section{Procedures}

The following section describes the methods, techniques, and data sources that guided our action research study into ways we implemented life skill lessons. These strategies were applied for 2 months during one English II Honors class at TTH, and one Language Arts class at $\mathrm{OTH}$, in addition to student lunch periods at OTH.

\subsection{Strategy 1: Interest Surveys}

At the start of the school year, we administered interest surveys to our students, as well as ten 
educators. The interest surveys consisted of 32 life skills, in which participants were encouraged to choose up to ten they felt were most important. We reviewed the answers from all of our students, but focused specifically on the answers of our six inquiry study participants. The interest survey served to provide baseline data for determining the life skills deemed most important by our students, and the educators in the study. Their selections were used to inform our creation of lessons.

\subsection{Strategy 2: SMART Goals and Self Reflection}

Another strategy we implemented consisted of SMART goals, followed by self-reflection (Nakata, 2016). Newman (2012) states that goal setting helps students manage priorities and remain on task while driving with pride toward success. Survey data led us to realize our students needed to first understand basic skills, such as goal setting. As sophomores preparing for exams in a few short months, we saw an opportunity for students to take ownership of their learning by setting realistic and relevant goals, and simultaneously creating a plan to manage their time towards those goals. We applied the SMART goal framework because of its clear step by step breakdown (Newman 2012). In class, students were asked to state: S- the specific goal, M- measure the time frame of the goal, A- if/why the goal was attainable, R- why the goal was realistic/relevant and T- specifically how they would manage their time in order to achieve the goal. After learning the parts of a SMART goal, students set a goal for how they wanted to do on their midterms, and followed that goal with a time management plan to prioritize their time leading up to the exams. Approximately three weeks after students set the initial goals, we asked them to reflect on their progress. Students completed a graphic organizer to reflect on the steps taken to reach their goal, as well as to determine what steps were left to complete. Based on their reflections, students revised their goals and time management plan, as needed.

\subsection{Strategy 3: Small Group Social Skills Instruction}

In accordance with Lindsey and Mabie's (2012) recommendations, we implemented social skills instruction. Prior to small group instruction, we held whole group discussions introducing the topic of social skills. We discussed appropriate communication techniques for talking to an adult compared to a peer. We also discussed how one should communicate during uncomfortable situations. Group discussion was ignited by posed questions including, "how would you respond to someone who was attempting to engage in a conversation you didn't want to be a part of?" and "how could you inform someone of an issue you're having with them, without sounding cruel?" Discussions were followed by opportunities to model appropriate conversational techniques, role play various social scenarios, or analyze social situations through the use of video clips and stories. Students engaged in a total of two lessons each week for a total of eight weeks.

\subsection{Data Collection and Analysis}

Data was compiled for two months using interest surveys, semi-structured interviews, anecdotal notes, and student/teacher reflections.

Interest surveys were administered to our six students and ten educators, one time at the start of the study. As mentioned above, participants documented ten life skills of interest to them. The 
data provided us with baseline information that aided in determining what skills we should provide instruction on, as we moved forward.

One 90 minute interview was conducted with each of the two OTH graduates at the start of the study. The interviews were recorded and transcribed immediately. Interviewees reviewed the transcriptions to ensure their responses were accurately represented. Additionally 15 minute, semi-structured interviews were conducted with the ten educators at the beginning and then mid-way through the study; responses were documented through anecdotal notes, and then reported back to the educators for their approval. Anecdotal notes were also collected up to three times a week while observing students apply social skills taught in lessons. Notes indicated if and when students were able to utilize the appropriate skills when interacting with others.

Student reflection was facilitated three weeks after the initial goal setting process. Students were invited to reflect on their academic progress leading towards midterms. Likewise, teacher reflections were completed up to three times a week reflecting on student achievement. The teacher reflections were stored in the same journal with anecdotal notes.

Data analysis was ongoing throughout the study, in order to use findings to drive instruction. Open coding, memoing and categorizing were used to identify patterns and derive themes that informed our research question (Dana \& Yendol-Hoppey, 2009). Initially, each data collection method was separately analyzed, simply to get an idea of trends surfacing within each method. Then, all findings from the multiple data sources were integrated to provide deeper insight into potential patterns being identified.

Responses from both student and educator interest surveys were entered into graphs to help us identify trends. We then triangulated interest survey results from educators, student reflections, and interviews from recent graduates, to seek patterns across contexts. Recurring patterns such as, frustration were coded in blue, the need for follow-through was coded in green, and challenges related to lack of social skills were coded in pink. In another round of analysis, anecdotal notes, interviews and our own self-reflections were corroborated, and coded similarly.

Data was shared with graduates and teachers to determine if perspectives were accurately represented, and had changed or remained the same after the study. In doing so, we aimed to establish trustworthiness in our findings.

\section{Findings}

Our analysis resulted in four major themes, each of which we describe below.

\subsection{Planning Life Skills Instruction Can Ease Student and Teacher Frustration}

Upon introducing this topic, it was immediately clear that the subject of 'Life Skills' was interesting to our students and fellow educators. This was something our students could relate to and wanted to learn more about. What we found most interesting about the interest surveys were the behaviors observed while students took them. Having taken the survey at the same time, two students discussed some of the options they chose immediately afterwards. They 
compared responses, and began discussing the ones they agreed upon. With frustration in his voice, Frank said, "Why don't any teachers teach this? It's so dumb." Jeff asked us personally "What's a credit score? I know it's important but I don't really know what it is." We explained what a credit score was to Jeff, and how even a small credit mistake as a young adult can impact an individual's future. He then went back to his survey and checked off 'Credit Score' as one of the life skills he wanted to learn more about.

Interactions between the students made it clear they were willing to take educational time to learn more about life skills, because they understood these were concepts that would assist them in their post-secondary lives. One learner asked, "Are all of the classes going to learn this stuff? Because they should!" Students felt like they had limited time to learn about all the concepts they felt they should have been learning for years. When we mentioned that we would be focusing on a few specific life skills over the course of the year, their overall demeanor changed to reflect a sense of ease, and they asked questions like, "When are we going to do this?"

Data also indicates that teachers felt a sense of frustration with regard to teaching life skills. Several expressed that there were so many things they wanted students to know, but not nearly enough time to implement them. Teachers also shared frustration that many of the skills were not built into curriculum already. One math teacher stated, "I teach math every day. I know it's important, but what about teaching students the math concepts they'll need for the future, like interest rates, credit scores and budgeting? Those are really important math skills too." His statement sparked a conversation among teachers about the importance of teaching these various skills, as well as ways to specifically add them to the curriculum. The conversation proved meaningful to the teachers, as the charter schools' guidelines encourage them to design and implement class curriculum to best serve their students' needs.

\subsection{Realistic Implementation is Crucial in Acquisition of Life Skills}

In all academic and social contexts, the actual utilization of a skill must be put into practice in order for an individual to truly grasp the concept. Our students expressed many times throughout the duration of this study that they had heard of, or were generally aware, of the various concepts we were introducing. However, their knowledge of the concepts ended when asked how these skills could be personally implemented in their lives. Baseline data informed us our students knew it was important to set goals, but actually preparing and planning to achieve them was a concept they had not mastered. Ensuring that we taught our students skills to follow through with personal utilization was apparently essential.

In preparation for their upcoming midterms, students created SMART goals. We noticed in a few cases, students gave themselves specific letter grades they wanted to reach. Sylvie wrote, "I want to achieve an A on my Marine Science exam and a B on my Pre-Calc Final Exam." Students also specified how they would reach their goal. Frank wrote, "I will go over any graphic organizers or any visuals from class to give me a clear understanding of certain topics." It was exciting to see students thinking about the process it would take to accomplish their goals, as well as recognizing the fact that there were necessary steps to take in order to achieve them. 
The students we worked with were familiar with expressing goals writing. Jeff said, "We do this in a lot of our classes. Mrs. R always makes us write goals." However, the time management plan was a new concept to them. Although it was encouraging to hear that other teachers were incorporating life skills like goal setting, it made it more apparent that teaching students how to follow through with their goals was equally as important.

After a few weeks, we had students revisit their initial goals. They filled out a graphic organizer that asked them to specifically reflect on their progress. They were asked to explain what they'd done so far to prepare for midterms, and what they still had left to do to achieve the goal. Then, they were asked to develop a new SMART goal if they felt as though theirs had to be revised. As students reflected, they made comments like, "I've set goals before, but usually I just make a goal and then forget about it." Frank said, "I've learned about why it's important to set goals, but no one has asked me to reflect on my goal; so usually I just move on and forget about it."

Frank specifically found success in goal setting through the use of the SMART goal strategy as he expressed that for the first time, he actually learned how to follow through with a plan. In using the SMART goal strategy for midterm planning, Frank demonstrated his connection between the goal he set for his upcoming midterm and the need for goal setting in future encounters, such as college and career planning.

Their shared goal setting experiences reinforced our belief that follow through was a crucial aspect of teaching life skills. It's not enough to just teach the topic; students have to actively engage, reflect and incorporate the topic into their lives to truly understand how it impacts them personally.

\subsection{Social Skills Are a Necessary Component of Life Skills Instruction}

After interviewing recent high school graduates, it became apparent social skills were a life skill that young adults felt strongly about mastering, prior to adulthood. Participants stated, "I don't have trouble connecting with people because I'm pretty social. I can talk to everyone, social skills taught me how to make connections with people." Perhaps this was especially evident, given that at OTH all students are challenged by a health-related disability that impacts their education, often affecting their ability to socialize with others in an age-appropriate manner. By explicitly teaching our students social skills, we realized that they would be more confident to address their opinions, as well as others appropriately. This seemed especially important to us, given the challenging world we are preparing them for.

Upon observing Jerry and David's interactions, we realized their great need for social skills, including initiating conversations, dealing with confrontation appropriately, and showing respect during disagreements. Jerry and David shared the exact same class and lunch schedule. However, they were often frustrated with each other and struggled to express reasons for their frustration. During lunch, we invited Jerry and David to sit together three days a week to observe their use of the social skills learned in class. Initially, we did not intervene when we saw them argue with each other. We waited to see if they could recall and apply their skills to rectify the problem. 
During the first two days, arguments resulted in each of them coming to me to complain. On the third day, we sat at the end of their lunch table and redirected them with a reminder of appropriate ways to express their feelings, upon witnessing them irritating each other. Each reminder was documented by a tally mark. Then it happened...Jerry began to explain to David that he was bothered by the way he ate his food and then burped at the lunch table. David explained to Jerry that his friends do the same thing, and he think it's funny. Instead of Jerry responding in a combative manner as we had seen him do in the past, he took a moment and thought about what David had said. Jerry then asked, "Can you say 'excuse me' when you do it?" David nodded his head. We were most impressed with the way Jerry took a moment to process what David had said before reacting and we rewarded both boys an "Act of Kindness" school-wide reward.

As a class, we discussed the situation that occurred at lunch, and students shared their opinions of how else they could have handled it. Jerry raised his hand and said, "I didn't yell at David, even when he was bothering me." He displayed a sense of pride in his behavior. We took this moment to further explain there would be situations in the future where they disagreed with what others were doing, or with what others believed in, and yet, they would need to be able to communicate appropriately when such situations arose. For the remaining lunch periods during the following three weeks, we documented the number of times we redirected students with appropriate social skill reminders, by marking tallies in our anecdotal notes. With each lunch period experience, the number of tallies lessened. In addition, the boys improved their social interactions, and limited redirection became necessary.

Students at TTH spent time reflecting on their social skills. They were asked to discuss the differences in socializing with adults compared with peers. Students expressed a general understanding that adults deserve to be spoken to in a more respectful manner, whereas with peers, they could be a bit more relaxed. Specifically, Grace stated, "When speaking to adults, I speak in a professional manner. For example, whenever I talk to my parents' friends, I make eye contact, speak professionally and I don't use any slang." However, of speaking to her friends, she said, "When talking to my friends, I tend to use sarcasm and slang. I am nowhere near as professional with my friends as I am with adults."

Students then participated in a Socratic seminar for an English class. Before the seminar, we reminded them the proper use of social skills depended on the setting. In a Socratic seminar setting, students were required to act more professionally with peers. Our anecdotal notes indicate that students struggled initially to interact with each other without the use of slang statements. Joe, for instance, began discussion stating, "Yo Lucas," and then quickly remembered the setting he was in and the expectations. He adjusted his response and said, "Lucas, I agree with what you're saying, here's what I think." After the seminar, I asked students to reflect on the use of their social skills. Frank stated, "It was hard at first to remember I couldn't just respond to my friend as I normally would. I had to remind myself where I was and what was expected of me." Their responses served as key moments of awareness for us, leading to the understanding that before students can advance to learning more complex life skills, they have to first understand how to appropriately communicate in various settings. The results of these conversations informed us our students needed continued social skills 
instruction.

\subsection{Beyond Study Participants}

While six students primarily informed our study, it is critical to note that whole classes completed the life skills lessons and strategies we facilitated. Thus, we have selected to share meaningful and noteworthy insight into our research question gained from students beyond our study's participants. In particular, we focus in on Sawyer, a student at OTH who comes from a low socioeconomic background.

After taking the initial interest survey, Sawyer said he went home and talked to his parents about the various skills listed. He shared with them that credit cards and credit scores were options to choose from. Sawyer's father informed him that at his age he had opened a credit card, and maxed it out immediately. His father stated he hadn't realized how much work it required to pay off the credit card each month. Further, only paying the minimum led him to acquire a lot of debt; debt he continues to pay today. Upon returning to school, Sawyer urgently reached out to us, stating, "I want to learn about budgeting and what it really means to have a credit card and what a good credit score is before I'm an adult, because I don't want to end up with the stress my dad feels each month he has to scrounge up money to pay for the mistake he made when he was my age." Sawyer's story resonated with us, as it confirmed a rationale for why students must learn life skills before they venture into adulthood.

\section{Implications}

This action research study has had a significant effect on our personal understanding of our responsibility as adults in the teaching profession. We came to realize that our obligation must go beyond teaching, as we are responsible for helping develop young adults preparing for a world outside of our classroom and school. Moreover, we feel fortunate to have an audience of young minds every single day. Our role requires us not just to influence them academically, but also socially and morally. As a result of this study, we have become more appreciative of our profession, and feel motivated to continue reaching our learners through meaningful life skill instruction.

Implementing realistic life skill lessons means listening to our students. Our learners looked at this as an opportunity to express their interests and curiosities about skills needed to succeed in adulthood. They were able to communicate their concerns with the curriculum, thus empowering them to play an active part in their education. Such involvement encouraged them to speak, well knowing they were being heard. Given this, it has become a major priority of ours to ensure that students recognize that they each have a voice to enact positive change in their own lives, as well as in the world.

As we listened and guided their interactions, we also heard ourselves. It wasn't too long ago that we were in their shoes, and yet in the midst of the demands of standards and of the curriculum, we had forgotten how their experiences and needs related to ours at their age. The realization led us to use life skill instruction to connect with our learners, thus creating meaningful learning experiences, and resulting in deeper, more trusting relationships. We have learned that spending time to genuinely listen to their stories contributes to implementing 
realistic life skill lessons.

This study confirmed our passion for developing and teaching life skills content to high school students. It is blatantly clear to us how direly needed these skills are in today's schools, specifically in contexts like OTH, which serve students with varying learning disabilities. Despite chaotic days, we made life skills instruction a priority, even implementing it during less structured times, including lunchtime and during casual, unstructured conversations with students throughout the day.

We have heard educators argue it can be hard to find content that students want to learn about in their content-specific classrooms. Thankfully, the concept of life skills is something our students really wanted to participate in. Still supporting our mandated standards, we were able to merge our English class content with life skills, and we believe that other can also do so, through creativity. While it is true there is never enough time to teach everything that we feel needs to be taught, targeting students' interest and needs, and strategically planning, made it possible for us to do so while adhering to the set standards. We like to believe our study is a realistic representation of ways that others can implement life skills in their daily classroom practice also.

After observing how engaged our students were during this study, it became more apparent that life skills content should be infused into core classes. However, we understand the many challenges teachers face in their daily contexts. Given this, we are led to wonder, in what ways can we empower fellow educators to implement life skills instruction in their secondary classes? We highly anticipate investigating this future query.

\section{References}

Anonymous. (n.d.). Florida English Language Arts Content Standards. Retrieved November 14, 2017, from http://www.cpalms.org

Bierman, K. L., \& Furman, W. (1984). The effects of social skills training and peer involvement on the social adjustment of preadolescent. Child Development, 55, 151-162. https://doi.org/10.2307/1129841

Choi, D. H., \& Kim, J. (2003). Practicing social skills training for young children with low peer acceptance: A cognitive-social learning model. Early Childhood Education Journal, 31, 41-46. https://doi.org/10.1023/A:1025184718597

Dana, N., \& Yendol-Hoppey, D. (2009). The Reflective Educator's Guide to Classroom Research: Learning to Teach and Teaching to Learn through Practitioner Inquiry (2nd ed.). Thousand Oaks, CA: Corwin Press.

Garrote, A. (2017). The relationship between social participation and social skills of pupils with an intellectual disability: A study in inclusive classrooms. Frontline Learning Research: An Official Journal of EARLI, 5(1), 1-15. https://doi.org/10.14786/flr.v5i1.266

Lindsey, T., \& Mabie, B. (2012). Life skills yield stronger academic performance. The Phi Delta Kappan, 93(5), 33-36. https://doi.org/10.1177/003172171209300508 
McCarthy, J. (2014). Learner Interest Matters: Strategies for Empowering Student Choice. Retrieved November 15, 2017, from https://www.edutopia.org/blog/differentiated-instructionlearner-interest-matters-john-mccarthy

McLeod, S. A. (2012). Zone of proximal development. Retrieved from http://www. simplypsychology.org/Zone-of-Proximal-Development.html

Meyer, K., \& Wurdinger, S. (2016). Students' Perceptions of Life Skill Development in Project-Based learning Schools. Journal of Educational Issues, 2(1), 1-24. https://doi.org/ 10.5296/jei.v2i1.8933

Nakata, Y. (2016). Promoting self-regulation through collaborative work: Insights from a multiple case study of foreign language learners. EuroSLA Yearbook, 16, 59-84. https://doi.org/10.1075/eurosla.16.03nak

Pesce, C., Marchetti, R., Forte, R., Crova, C., Scatigna, M., Goudas, M., \& Danish, S. J. (2016). Youth life skills training: Exploring outcomes and mediating mechanisms of a group randomized trial in physical education. Sport, Exercise, and Performance Psychology, 5(3), 232-246. https://doi.org/10.1037/spy0000060

Prajapati, R., Sharma, B., \& Sharma, D., (2017). Significance of Like Skills Education. Contemporary Issues in Education Research, 10(1), 1-6. Retrieved November 14, 2017, from http://files.eric.ed.gov.esearch.ut.edu/fulltext/EJ1126842.pdf

Ramey, L. (1984). A Life Skills Program for Incarcerated Offenders: Origin and Development. Journal of Correctional Education, 35(2), 50-53. Retrieved from http://www.jstor.org. esearch.ut.edu/stable/41971284

Rateau, R. J., Kaufman, E. K., \& Cletzer, D. A. (2015). Innovative Classroom Strategies That Prepare College Graduates for Workplace Success. Journal of Agricultural Education, 56(3), 52-68. https://doi.org/10.5032/jae.2015.03052

Sobel, D. (2004). Place-Based Education: Connection Classroom and Community. Nature and Listening. Retrieved December 5, 2013, from http:/www.antiochne.edu/wpcontent/uploads/ 2012/08/pbexcerpt.pdf

Swank, J. M., \& Huber, P. (2013). Employment Preparation and Life Skill Development Initiatives for High School Students with Emotional and Behavioral Disabilities. The Professional Counselor, 3(2), 73-81. https://doi.org/10.15241/jms.3.2.73

United Nations Children's Fund. (2015). The Investment Case for Education and Equity. UNICEF Education Section, New York, NY.

Venezia, A., \& Jaeger, L. (2013). Transitions from High School to College. The Future of Children, 23(1), 117-136. https://doi.org/10.1353/foc.2013.0004

Yadav, P., \& Iqbal, N. (2009). Impact of Life Skill Training on Self-esteem, Adjustment and Empathyamong Adolescents. Journal of the Indian Academy of Applied Psychology, 35(Special Issue), 61-70. Retrieved from http://medind.nic.in/jak/t09/s1/jakt09s1p61.pdf 


\section{Copyright Disclaimer}

Copyright for this article is retained by the author(s), with first publication rights granted to the journal.

This is an open-access article distributed under the terms and conditions of the Creative Commons Attribution license (http://creativecommons.org/licenses/by/3.0/). 